\title{
A Summary of the Development of Wushu Education for Overseas Students
}

\author{
Qizheng Chen
}

\begin{abstract}
Xincheng Street 2888, Department of Military Physical Education ,Jilin Agricultural University, Changchun, Jilin Province 130118, PR China
\end{abstract}

704170168@qq.com

\section{Keywords: Overseas students; Martial arts education; Development review}

\begin{abstract}
The education of overseas students is an important part of the development of education in colleges and universities in China, and has been paid more and more attention. Therefore, it is necessary to develop the education of college students. The development of overseas student education not only can promote the reform of higher education in our country, enhancing the competitiveness of colleges and universities, but also promote the local regional culture through the education of foreign students, enhance the international influence of the city, and promote the comprehensive strength of ordinary colleges and universities have played a positive role in promoting. The study of the development of overseas students' martial arts education can understand the practical significance of the development of Wushu education for overseas students from the perspective of development. The study on the development of Wushu education is an important part of the development of Wushu education. Which can improve the rational understanding of the development of Wushu education for overseas students, and play a certain role in promoting the sustainable development of Wushu education.
\end{abstract}

\section{Concept Definition}

This paper mainly explores the current situation of Wushu courses for overseas students in Jilin in Jilin province, mainly related to foreign students, martial arts courses, traditional culture, harmonious culture related concepts.

A student who is studying or studying abroad. The term "student" is created by the Japanese. The term "international student" refers to a student who has a non-Chinese nationality (except Hong Kong, Macao and Taiwan) who are studying and studying in Chinese institutions of higher learning.

Martial arts (martial arts), boxing and the use of weapons technology, is the traditional Chinese sports. ("Modern Chinese Dictionary") martial arts, also known as martial arts or martial arts. The content is to kick, hit, throw, take, fall, hit, split, thorn and other actions in accordance with certain laws composed of hand and equipment of various offensive and defensive fighting effort, routine and single potential practice. Which is the Chinese in the long-term social practice in the accumulation and enrichment of a valuable cultural heritage, and which is one of the outstanding cultural heritage of the Chinese nation. The concept of martial arts is defined by the State Sports General Administration as: martial arts is the main content of technical action, with routine and fighting as the form of movement, focusing on the traditional Chinese and foreign sports, is an integral part of Chinese traditional culture.

The traditional culture of China is a national culture which reflects the national characteristics and style of Chinese civilization. It is the overall representation of all kinds of ideology and culture and ideology in national history. It refers to the traditional culture living in China of the Chinese nation and its ancestors to create, for the Chinese nation inherited from generation to generation. With distinctive national characteristics, what has a long history, profound connotation, traditional fine culture. It is the crystallization of the Chinese nation for thousands of years of culture, in addition to the core content of Confucian culture, but also contains other cultural forms, such as Taoist culture, Buddhist culture and so on.

Harmonious culture should reveal the relationship between people and people, the relationship 
between people and society, the friendly relationship between man and nature, the relationship between man and the self, and is committed to the coherence and benign interaction of these relations. In a word, the essence of a harmonious culture lies in thinking with a harmonious way of thinking, the key to a harmonious cultural construction is to use harmonious ideas to promote development. At present, the academic understanding of "harmonious culture" is diversified, one of which is understood as a harmonious culture as the center of the cultural concept, can be called "on the harmonious culture", " The culture of harmony as the main content ". This is from the type of culture on the "harmonious culture" to define, that is different from other cultural styles constitute a specific cultural patterns. As a self - contained cultural type, the author believes that the construction of a harmonious culture is based on the natural concept of harmony between man and nature, and the different ways of thinking, the value orientation of Datong thought.

\section{A Study on the Development of Wushu Education for Overseas Students in China}

Chinese overseas students education has experienced the national task, semi-self commitment, independent commitment to three stages, from the early days of the founding of our country's international education for the country will change, experienced a number of government and education sector efforts to develop so far. In the early days of the founding of our country, the education of overseas students existed in a certain state-dominated form. The education of overseas students was to fulfill the internationalist obligations of the socialist countries. After the reform and opening up, Chinese overseas students in the scale of the growing, at the same time the martial arts courses due to the requirements of overseas students and students continue to improve the training program, and gradually boarded the big stage of student education, and in practice by a lot of students of love.

At present, the number of international students in our country has increased year by year. According to the development goal of "National Medium and Long Term Education Reform and Development Plan (2010-2020)", by 2020, China will become the largest destination country in Asia, Reaching 500,000 people, of which more than 150,000 students receive higher education.

\section{A Study on the Significance of the Development of Wushu Education for Overseas Students}

The Internationalization of National Traditional Culture Needs: The rapid development of the era of knowledge economy, the continuous development of information technology, close to the distance between the world, to speed up the integration of Eastern and Western cultures, but also to the inherent development of oriental culture has brought challenges. Chinese traditional culture has a certain harmony, the doctrine of the mean, in the cultural transmission by the strong impact of Western culture, how to achieve the international development of national traditional culture is the trend of our traditional national culture. Countries in different countries, according to their different political, economic base and historical and cultural characteristics, in the deployment and implementation of the internationalization of higher education strategy, adopted a different approach, through a different process.

The education of overseas students should be related to the national political system, the national ideology, the cultural transmission, the development of international education and the national folk customs. Many influencing factors are destined to the particularity of overseas students' education. During the period of living in China, life, education and social interaction will be influenced by the traditional culture of our country. However, due to the great differences between the cultural background of foreign students and the traditional culture of our country, how to show our traditional culture and make students more understandable and vividly. Which can master the essence of traditional culture is the need for college educators to think carefully. Wushu movement is an important part of traditional culture of our country, which is a body culture without language barrier. The tradition of martial arts is not only the spread of national martial arts concept, but also the spread of traditional culture. The use of martial arts communication has certain advantages and characteristics, through the international students martial arts courses to expand our traditional 
culture to the world approach, therefore, in-depth study of institutions of higher learning students martial arts courses on the international development of national traditional culture can play a positive role in promoting, which has a certain cultural value.

Promote the Internationalization of Higher Education in China: At present, the development trend of world education presents lifelong education, student-centered and higher education internationalization of the three major trends, at the same time, many colleges and universities attach importance to scientific research, expand new way, the international development of many domestic institutions of higher learning the next step development focus. The internationalization of higher education and the western developed countries, the internationalization of higher education is the development of the information age and the important component of economic and social development, the internationalization process has become the only way for the development of colleges and universities corresponding to globalization, School development potential and the quality of teaching an important indicator. The development of international education The internationalization of institutions of higher learning is mainly reflected in the activities level, the level of competence, the cultural level and the process level. As a special group, the international influence is not only to improve the international status of our university, but also an important position for the international development of Chinese higher education. The martial arts curriculum is characterized by its special national and physical culture The traditional way has become a special symbol of the internationalization of higher education. The national character of martial arts is the characteristic of its favorite students. At the same time, the cultural nature of body language is able to express the living culture of higher education in our country. has the characteristics of traditional Chinese difference in international higher education teaching approach. Therefore, the martial arts education of overseas students can actively promote and promote the internationalization of higher education in China, with a certain educational value.

The Realistic Needs of International Student Education in China: The complete teaching system should be the diversified education of "moral, intellectual and physical" comprehensive development. The special nature of the overseas students determines that the education system of higher education in our country should have the educational policy of "moral, intellectual and physical development" With the 2008 Beijing Olympic Games held, martial arts as a unique national culture of the Chinese nation during the Olympic Games to show the world, the unique charm of Chinese martial arts deeply attracted the interest of overseas students. According to the statistics of the Ministry of Education, the number of overseas students in our country is on the rise, and the martial arts curriculum will become a compulsory course for overseas students in China. At the same time, the martial arts courses of Chinese students in China are facing teaching ideas, teaching management and course content set up, personnel training programs and many other issues. To solve the problem of overseas students' martial arts is an important issue in our country's education, practical problems, more colleges and universities have realized the importance and reality of the international martial arts courses, and actively seek solutions to improve and improve the overseas students understand the way and vision of Chinese traditional culture in China. This study takes the traditional culture as the core, takes the college martial arts curriculum as the carrier, uses the college student education to inherit the national traditional culture, according to Jilin province university student martial arts curriculum establishment situation, summarizes the experience, studies the corresponding problem solving plan, increases our country traditional culture dissemination of the way for the development of national traditional culture to provide a reference.

Improve Students' Understanding of Chinese Traditional Culture: Foreign students come to China to study Chinese as the mainstay, but the understanding of traditional culture is an important component of learning Chinese, and foreign students martial arts courses in the interest of international students and improve the understanding of Chinese ability to play a double role, both to meet the interest of students, But also through the Chinese martial arts learning to understand the traditional Chinese culture learning to understand the profound connotation of traditional Chinese culture. Wushu in the martial arts curriculum contains a wealth of national cultural characteristics 
and traditional ideas, while the cultural connotation of martial arts is an extension of traditional Chinese culture. The cultural connotation of martial arts is not only a single sports theory, but also a portrayal of a national traditional culture, the use of physical culture to show the traditional culture of martial arts is unique, more able to make students deeply understand the connotation and experience of the charm of traditional culture on the traditional Chinese culture. This paper investigates the campus culture characteristics of colleges and universities in Jilin Province and summarizes the traditional cultural transmission methods which meet the characteristics of Wushu curriculum students in Jilin province.

\section{Conclusion and Suggestion}

The development of overseas students education is one of the important signs to realize the internationalization of higher education in our country. It is an important way to develop the international education of Wushu students to realize the traditional culture to the world. Overseas students can better understand traditional culture through martial arts education, better understand China, and contribute better to traditional culture to the world.

\section{References}

[1] Li Ke. Beijing Normal University, the traditional national sports curriculum research to Beijing Language and Culture University as an example [D]. Beijing Sport University. May 2012

[2] Yuan Guiren. the notice of On the careful organization of learning Comrade Yuan Guiren "adhere to the Party's leadership and the direction of socialist education continue to promote the scientific development of education," [Z]. Qiu Shi .2011 (14)

[3]Ministry of Education. Notice on Initiating the "Study Abroad in China" [Z] .2010.9

[4] Chai Xin. Putting the Education of Foreign Students into the Internationalization of Higher Education - Some Problems and Countermeasures on the Work of Foreign Students in Tsinghua University. [J] Tsinghua University Educational Research, 2006.12

[5] Wang Wei, Gao Yanyi, Li Xindian. Heritage traditional culture of overseas students martial arts curriculum [J]. Mangzhong Literature .2013 (5:): 223-224

[6] Wu Song, Chinese martial arts theory of art [D], Suzhou University, 2011

[7] Li Jinghua, Gao Jinbao, on the relationship between martial arts culture and Confucianism, Taoism and Buddhism theory [J], Master, 201006

[8] Lu Yuanzhen, Sports Sociology [M] Beijing, Higher Education Press, 2001

[9] Du Shushu, martial arts humanistic interpretation [D], Northwest Normal University, 2004

[10] Chinese People's Education Department, Physical Education and Health Curriculum Standards 2005 